\begin{tabular}{|c|c|}
\hline BRTIISH MEDICAL JOCRNAL VOLLME 290222 J'NE 1985 & PRACTICE OBSERVED \\
\hline Practice Research & \\
\hline Managing alcohol problems in ge & neral practice \\
\hline PETER ANDERSON & \\
\hline 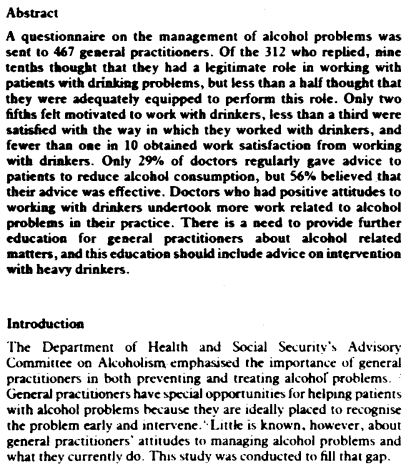 & 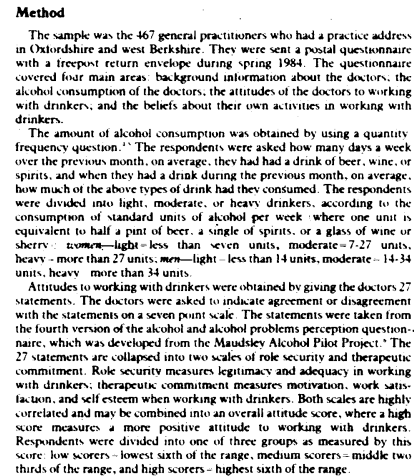 \\
\hline 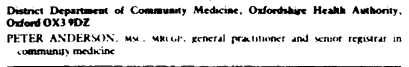 & 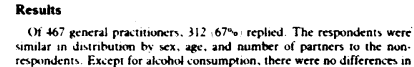 \\
\hline
\end{tabular}

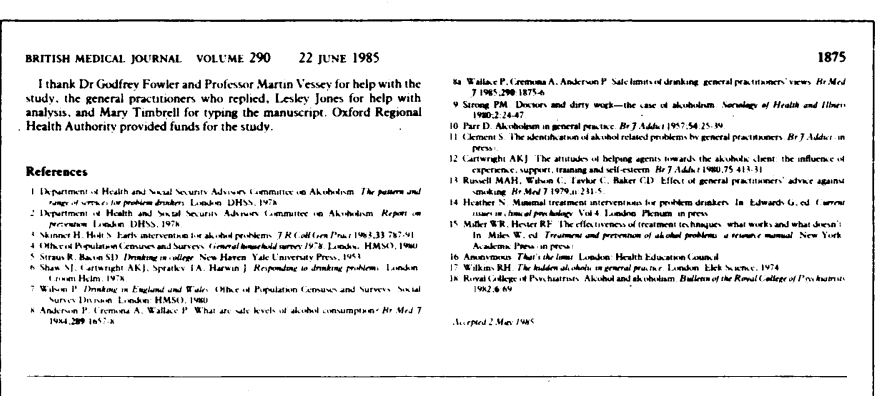

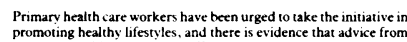

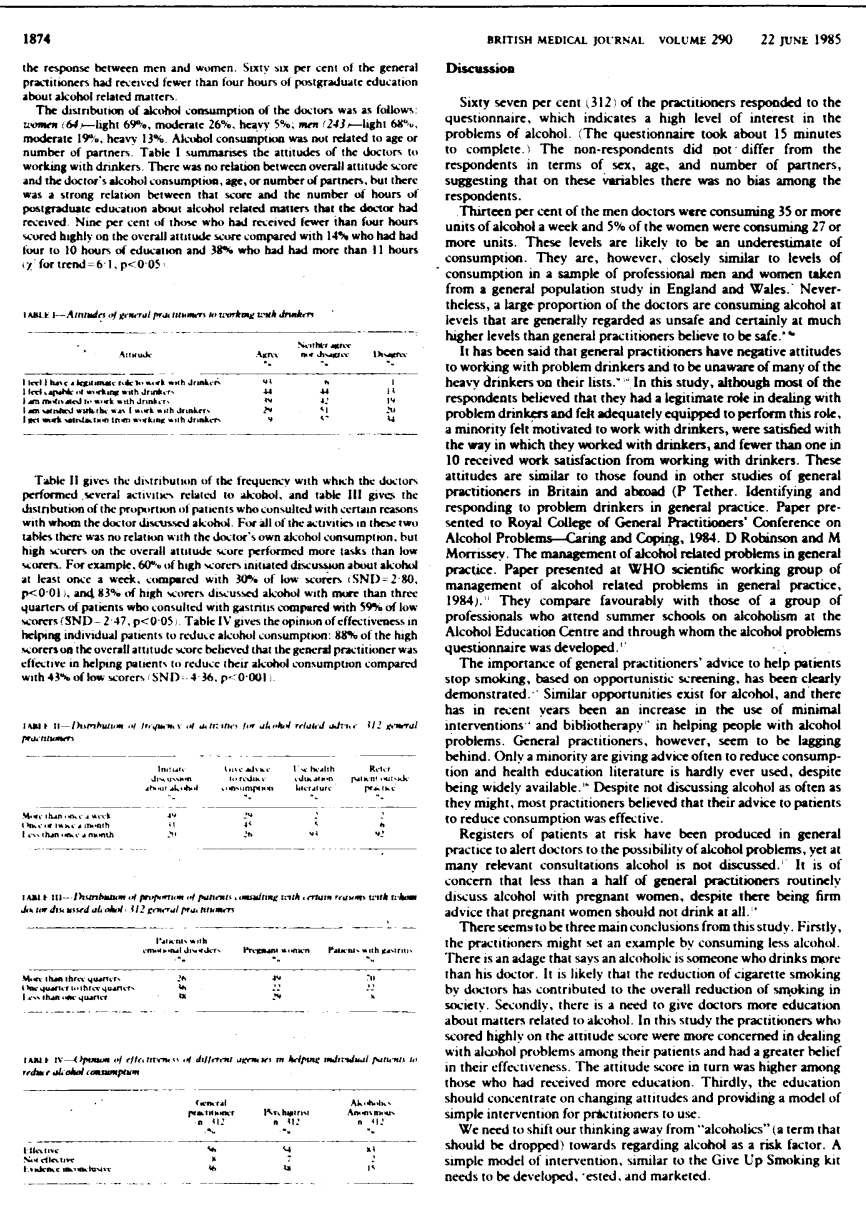

\section{Safe limits of drinking: general practitioners' views}

PAUL WALLACE, ANNE CREMONA, PETER ANDERSON

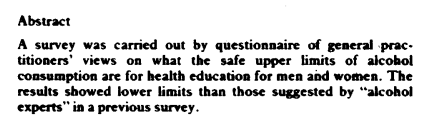

The results of a survey that we recently carried out showed that
there was a considerable lack of consensus on the yusstion of sate

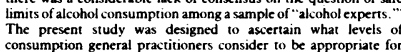

Introduction

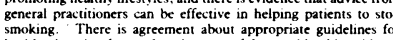

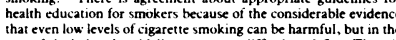

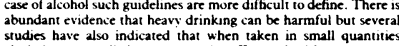

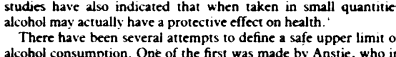

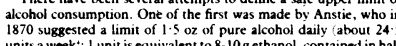

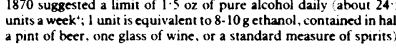

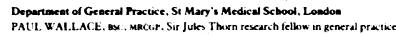

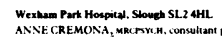

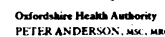

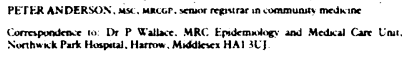

1876

Discussion

The high response rate supports she findings of a previous study
that suzgesseded that there is considerable interest among general

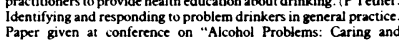

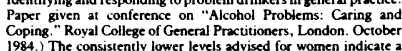

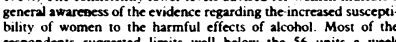

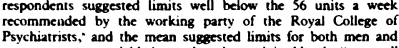

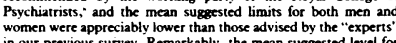

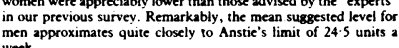

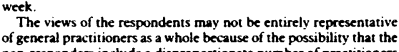

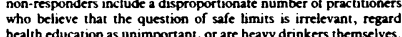

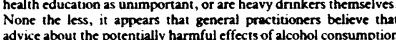

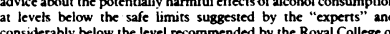

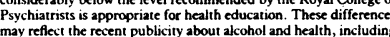

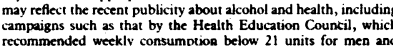

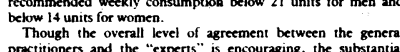

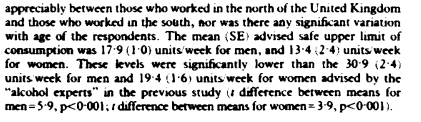

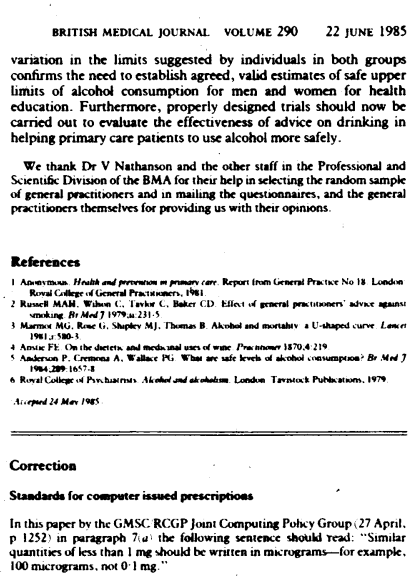

\section{Audit Report}

Cervical cytology in a Guildford practice

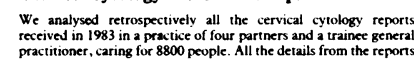

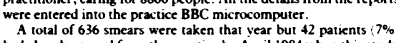

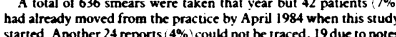

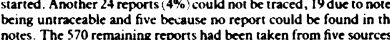

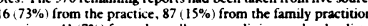

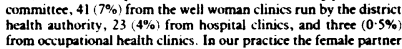
women under the age of 30 . Because the cares-sex profile nat been

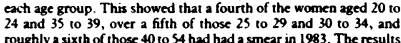

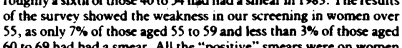

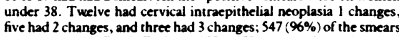

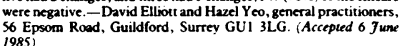

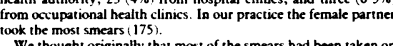

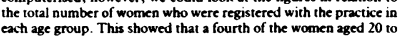

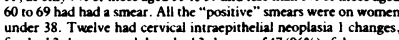

